\title{
NIPPLE LOCATION BY NEWBORN RABBITS: BEHAVIOURAL EVIDENCE FOR PHEROMONAL GUIDANCE
}

\author{
by \\ R. HUDSON and H. DISTEL ${ }^{1}$ ) \\ (Institut für Medizinische Psychologie, Ludwig-Maximilians-Universität \\ München, F.R.G.) \\ (With 4 Figures) \\ (Acc. 10-II-1983)
}

\section{Introduction}

One of the major tasks confronting newborn mammals is to find the mother's nipples and suckle. This requires that the young respond appropriately to the presence of the mother, that they find and secure a nipple, and that they suck effectively. Most mammals having altricial young spend long periods of time with their newborn litters while assuming the nursing posture. Cats (Schneirla et al., 1973), dogs (Rheingold, 1963) and rats (Grota \& AdLer, 1969) for example, spend up to $80 \%$ of the first few days post partum nursing.

Doe rabbits are unusual in that they give their litters very little behavioural assistance to suckle. They leave their pups almost immediately after giving birth, and with occasional exceptions, only return to feed them approximately every 24 hours (VENGE, 1963; ZARRow et al., 1965). Furthermore, the daily nursing period only lasts from about 2 to 4 minutes (Deutsch, 1957; Lincoln, 1974), during which does stand almost motionless over their pups (Hudson \& Distel, 1982). Rabbits are fugitive animals and heavily preyed upon. Presumably the less time does spend in their otherwise blocked nursery burrows, the less chance there is of predators trapping them there or finding the young (ZARRow $e t$ al., 1965). However, rabbit pups are born in a rather immature state. They are naked, have sealed eyes and outer ears and have poor motor coordination (GotTlieb, 1971). How the newborn pups are able to locate their mother's nipples and suckle in the brief time available each day is unclear, as their normal suckling behaviour has not been described.

1) This work has been supported by the Deutsche Forschungsgemeinschaft (Di 212/2-2) 
Laboratory studies have suggested olfactory stimuli to be important, and a pheromone on the nipples and in the milk releasing nipple grasping and sucking has been proposed (Schley, 1977; Müller, 1978). Otherwise, little is known about how the pups are able to suckle so efficiently.

It is the purpose of this paper to describe the suckling behaviour of rabbit pups under more natural conditions, and to experimentally investigate the role of the doe's ventral fur, skin, and of the nipples in enabling the pups to orient to their mother and to locate nipples.

\section{Animals and methods}

Rabbits, Oryctolagus cuniculus (L.), of an established chinchilla strain (Chbb) were obtained from Thomae (Biberach, F.R.G.), and bred in our facilities. A total of 21 test does (17 lactating, 2 pregnant and 2 virgin) and 19 litters was used in this study. The first three litters were reduced to three pups, and the other 16 to six pups each.

\section{Observational litters.}

The first three litters were raised in a plexiglass nest box (see HudSON \& DisTeL, 1982) and their suckling behaviour was observed and recorded on video from beneath until day 12 . Visibility was ensured by removing nest material before the does were allowed in to suckle each day at $8 \mathrm{a} . \mathrm{m}$. In addition, the belly of one doe was clean shaved for better observation.

\section{Tests of milk consumption.}

To test the importance of the does' fur for the pups' suckling performance, the bellies of two does were shaved the day before parturition, while two others were left unshaved. Litters were swapped between shaved and unshaved does each day until day 12, and milk consumption was estimated by weighing pups before and after nursing.

\section{Arena tests.}

For closer observation, all remaining litters were tested on does which were restrained on their backs in a U-shaped trough $13 \mathrm{~cm}$ wide and $17 \mathrm{~cm}$ deep. The ends of the through were closed by dividers which fitted the doe's body so as to form an arena $(18.5 \mathrm{~cm}$ by $13.0 \mathrm{~cm})$ which enclosed the six rear nipples. To record the behaviour of the pups, a video camera was installed viewing the arena and a digital timer from above. Pups were placed on the doe's belly with their nose at the center of the arena, and then released. They were removed again after they had sucked and released the first nipple, or after 30 seconds. Each pup was given 5 trials per test condition, and was rested for at least 15 minutes between conditions. Each doe and litter were only used in two conditions. For most conditions, the occurrance and duration of nipple search behaviour, and nipple grasping and sucking were scored.

Arena tests were performed on day 4 , six hours after nursing. In the first experiment, however, tests were also performed on days 8 and 12. In this experiment, four lactating does were used, two of which had shaved bellies. The performance of two times two litters on shaved and unshaved does was compared. Order effects were controlled for by dividing litters, and testing one half on a shaved doe first and then on an unshaved doe, and vice versa. In addition to the usual measures of performance, latencies to initiate nipple search behaviour and to reach nipples were measured at a $0.5 \mathrm{sec}$ level of accuracy.

In a further test, the belly fur of a lactating doe was removed in an intact strip, i.e. as a "fleece", by covering it with adhesive and gauze and shaving it close to the skin. Before 
making the fleece, adhesive alone (Scotch foto mount spray) was applied to the doe's belly fur and a litter was tested on the doe as soon it had dried. Then, after shaving, the fleece was laid flat with the roots of the fur uppermost, and the litter tested on it. Finally, pups were given one control trial each on the now shaved doe.

After a series of preliminary experiments not reported here, four more litters were tested on four shaved, lactating does whose belly skin, nipple areas, and/or nipples had been covered in different ways (conditions A-H, Fig. 4). Nipple areas were arbitrarily defined as zones of $30 \mathrm{~mm}$ diameter centering on the nipples, and rings of this diameter with a $5 \mathrm{~mm}$ hole were punched from an adhesive tape. These rings were placed around the nipples of the first doe, and the belly skin between them was taped over as well. Pups were tested under this condition (A), and then, after removal of the tape, with the rings alone (B). On the second doe, a fine nylon net $(1 \mathrm{~mm}$ mesh, $0.25 \mathrm{~mm}$ thread gauge) was placed tightly over the entire belly $(\mathrm{C})$. In the next condition (D), $15 \mathrm{~mm}$ rings were used and the nipples covered completely with a thin layer of a soft, fast polymerising rubber material (Kerr, Permlastic). On the third doe, the nipples alone were covered (E), and then after removal of the rubber, tighter rings ( $4 \mathrm{~mm}$ hole) covering the nipple bases were fitted $(F)$. On the last doe, nipples were about three quarters covered with rubber and with $15 \mathrm{~mm}$ rings ( $5 \mathrm{~mm}$ hole) so as to allow a narrow gap at the nipple base (G). In the last condition $(\mathrm{H})$, rubber replicas of nipples taken from plaster casts were glued (Histoacryl) next to the real nipples which had been taped over. Each pup was given one final control after conditions $\mathrm{B}, \mathrm{D}, \mathrm{F}$, and $\mathrm{H}$ when all coverings had been removed.

To test the influence of skin temperature on nipple location, a litter was tested on a lactating doe before and after small ice packs had been placed on the nipple areas. Finally, the behaviour of two litters on two 4-month-old virgin does was compared with their performance on two pregnant does ( 24 and 25 days gestation) and with their performance on the virgin does after their nipples had been painted with saliva from lactating does.

Where performance scores were not normally distributed, median scores are given and nonparametric statistical tests of significance used. The components of nipple search behaviour and points on the does' bellies at which pups started searching were traced by single frame analysis from the video screen.

\section{Results}

\section{Observations from below.}

The behaviour of the does and the pre- and postnursing behaviour of the pups observed from below through the bottom of a plexiglass nest box was similar to that observed earlier from above (Hudson \& Distel, 1982), and therefore emphasis will be given to new observations.

By nursing time the pups were huddled together and very active. They were sensitive to vibrations and tactile stimuli, and responded to a hand or piece of paper towel being lowered onto them with vigorous rearing movements of the head and forequarters, and with vocalization. This was also their response to the doe's entry into the nest box. Does very quickly assumed the nursing posture, taking on average 5.2 secs, and stood almost motionless over the pups. Rearing then helped the pups to establish the necessary contact with the doe's belly. They pushed their muzzles into the fur, and moved them rapidly from side to side while probing the belly until a nipple was found and secured. This took only about 
TABLE 1. Quantification of nest box observations of suckling behaviour at different ages

\begin{tabular}{lccc}
\hline Days post partum & $1-4$ & $5-8$ & $9-12$ \\
\hline Median latency to belly fur & $\mathbf{1 8 . 0} \mathrm{sec}$ & $\mathbf{1 1 . 5} \mathrm{sec}$ & $\mathbf{1 . 0} \mathrm{sec}$ \\
& 18.5 & 6.0 & 1.5 \\
Median search time to first nipple & $\mathbf{7 . 0 \mathrm { sec }}$ & $\mathbf{6 . 0} \mathrm{sec}$ & $\mathbf{6 . 0} \mathrm{sec}$ \\
& 9.0 & 2.5 & 4.5 \\
Rate of nipple changes per min & $\mathbf{1 . 5}$ & $\mathbf{2 . 6}$ & 3.9 \\
Average time spent on a nipple & $\mathbf{2 3 . 0 \mathrm { sec }}$ & $\mathbf{1 7 . 0} \mathrm{sec}$ & $\mathbf{1 2 . 0} \mathrm{sec}$ \\
& 9.0 & 6.0 & 4.5 \\
Average time spent between nipples & $\mathbf{9 . 5} \mathrm{sec}$ & $\mathbf{6 . 0} \mathrm{sec}$ & $\mathbf{4 . 0} \mathrm{sec}$ \\
& 6.5 & 5.0 & 2.5 \\
Percent of nursing session spent sucking & $\mathbf{4 7 . 3 \%}$ & $\mathbf{6 0 . 7} \%$ & $\mathbf{7 1 . 6 \%}$ \\
\hline
\end{tabular}

Semi-interquartile ranges and standard deviations for medians and averages are given in light print.

6 secs once their muzzles had contacted the belly fur. Although older pups made this contact immediately the doe stood still, younger pups had more difficulty and took considerably longer.

Pups showed no particular posture when suckling, and lay equally often on their sides, backs or bellies. While they kept their heads firmly over the nipple, their bodies might be jostled in any direction by vigorously searching litter mates. They appeared to effectively resist being pushed off nipples by pushing against offending litter mates with their heads. No specific posture or body movements associated with sucking or milk intake could be identified except that pups on a nipple braced their hind legs against the floor or littermates, and often made treading movements with their forelegs.

Pups did not remain on the one nipple during nursing. Even when undisturbed by litter mates, pups would suddenly release a nipple and jerk their head to the side. They then searched through the doe's fur again until another nipple, or less commonly the same one, was located. All pups showed this behaviour, and switched nipples at an average rate of 2.6 times per minute. They spent an average of 17.1 secs on any one nipple, and 6.4 secs making each nipple switch (Table 1). Although pups sometimes alternated between a pair of nipples, no systematic changes in nipple switching behaviour within nursing sessions, or nipple preferences were found.

During nursing the pup's bellies visibly increased in size, and all pups appeared to have reached the physical limit of milk intake before the end 
of nursing. Yet, they continued making vigorous searching movements and to take nipples until the doe left. As soon as she had gone, rearing and searching movements stopped and, after about 30 seconds quiescence, pups showed the typical post-nursing urination and digging movements (Hudson \& Distel, 1982).

Except for a longer nursing period on day 1 (10 and $12 \mathrm{mins}$ ), the nursing time of does remained fairly constant at 3-4 mins over the 12 days of observation. Although the pattern of the pups' suckling behaviour changed little, the percentage of nursing time spent on the nipples increased from $47.3 \%$ in very young, to $71.6 \%$ in older pups. This was soley due to the greater speed with which older pups reached the does' belly fur and initited nipple searching, as the time taken to locate nipples was counterbalanced by the rate of nipple switching (Table 1 ).

The role of fur.

Additional observations from below of a doe whose belly had been shaved for better viewing conditions suggested that pups had more difficulty reaching her belly than normal, and that fur may play a role in nipple location.

To test the effect of removing the belly fur on nursing performance, the milk consumption of four litters nursed by shaved and furred does on alternating days was compared. During the days that pups were nursed by shaved does they obtained $20 \%$ less milk than on the days they were nursed by furred does. Analysis of variance for repeated measures showed this to be a significant difference $(F=7.98$, d.f. $26 / 1, p<0.01)$. The behaviour of the shaved does appeared normal, and there was no significant difference in the time spent by shaved and unshaved does nur$\operatorname{sing}(F=2.09$, d.f. $2 / 1, p>0.29)$.

To observe the behaviour of pups on shaved and furred does more closely, does were restrained on their back and pups tested in an arena which enclosed the does' nipples. Nipple search behaviour shown in the arena was similar to that observed from beneath, but the arena observations had the advantage of enabling repeated testing and a more detailed analysis of behavioural components.

Pups placed on the bellies of normal, furred does responded by pushing their muzzles into the fur, and then moving their heads rapidly but erratically to either side independently of the fur direction. Lateral head swings were combined with vertical movements of the head bringing the snout into intermittent contact with the does' under-fur or skin. These probing movements continued until a nipple was located, and as it 
A

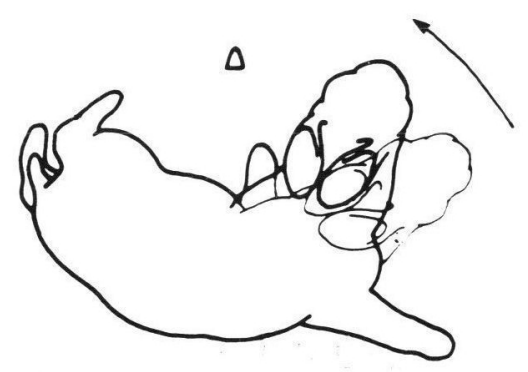

$\Delta$

C

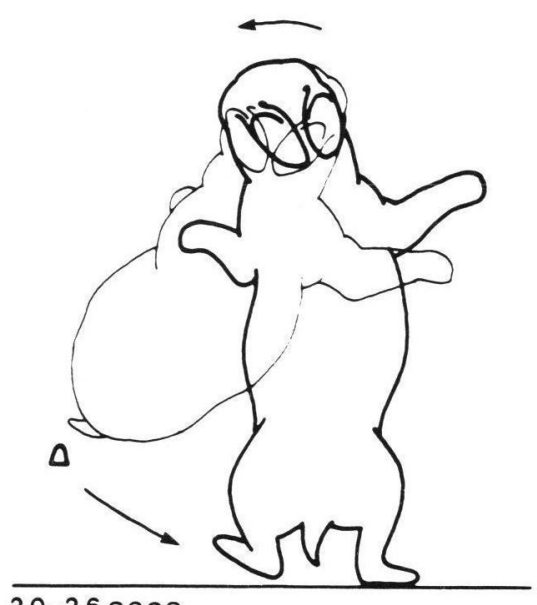

B doe 86
$\Delta$

$\Delta$.
$\Delta$

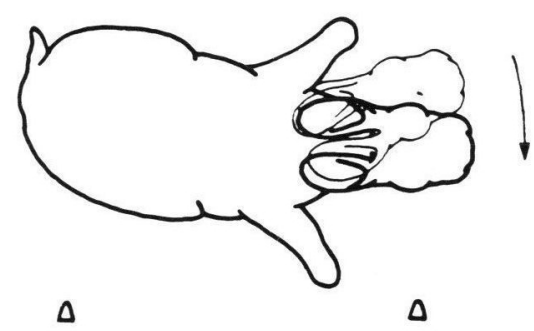

$0.4-2.5$ secs

Fig. 1. Schematic drawings of a 4-day-old pup's behaviour viewed from above on the ventrum of a furred doe (86) and a shaved doe (85) in the arena; A. head-swing component of searching behaviour, B. probe component, C. nipple grasping and bracing of the body following location of the nipple, D. slow movements before the perception of the searchreleasing odour. The does' nipple pattern, the time elapsed after placement of the pup on the doe, and direction of the pup's movements are also shown. 
was grasped, pups usually stretched out or arched their body, bracing it on the now extended hind legs (Fig. 1A-C). Searching behaviour was similar on shaved does except that pups were slower to bring their snouts into contact with the skin initially (Fig. 1D), and made fewer and smaller amplitude head swings. This decrease in the lateral head swing component and predominance of the vertical probing component resulted in pups being slower to move away from the site of first probing and across the bellies of shaved does.

Analysis of search pathways on day 4 demonstrated in addition that the starting points of probing movements were different on furred and shaved does. While pups on furred does probed almost immediately, and

\section{F URRED}
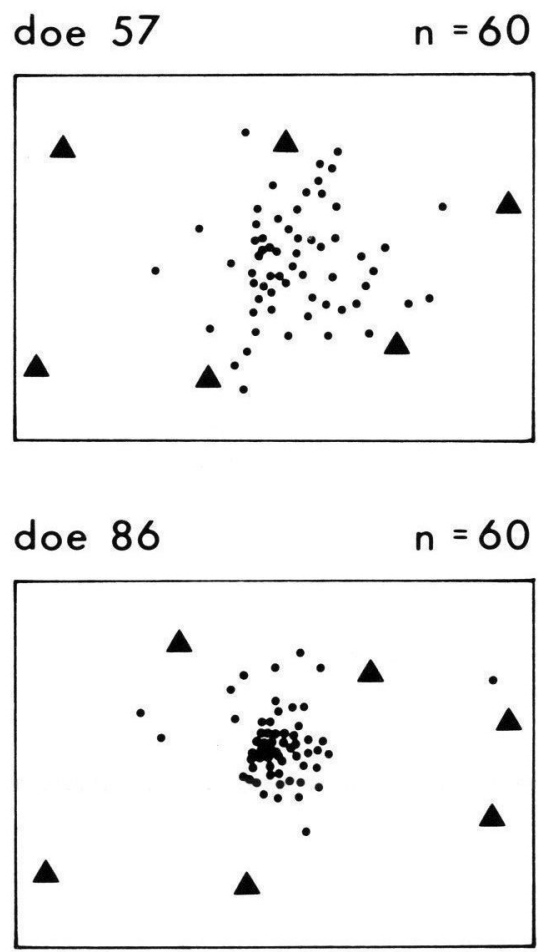

head

\section{SHAVED}

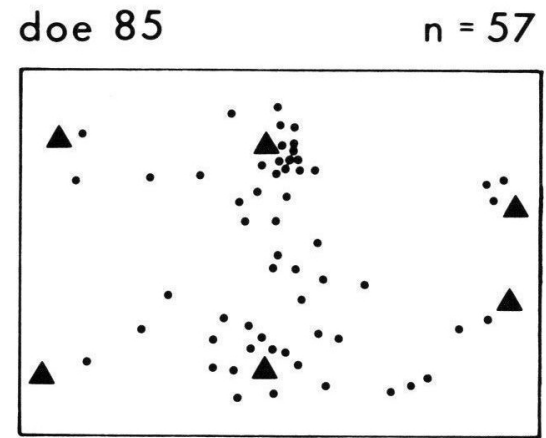

doe 34

$n=56$

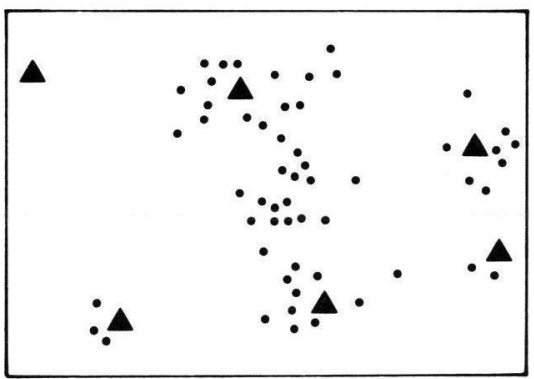

tail

Fig. 2. Distribution of first probing movements on furred and shaved does (day 4). Nipple patterns and arena boundaries are indicated. Not all trials resulted in probing on the shaved does. 
therefore usually in the center of the arena, on shaved does they had often moved away before probing. Starting points on shaved does were thus more widely distributed, although they appeared to be concentrated near nipples (Fig. 2).

Pups took a median time of 0.5 secs to initiate probing on furred and 1.0 secs on shaved does, and a median time to locate nipples of 2.0 secs on furred and 5.5 secs on shaved does. A comparison of the performance of the four litters in the two conditions using the Friedman two-way analysis of variance by ranks showed both the times taken to initiate probing, and to reach a nipple to be significantly shorter on furred does $\left(\chi r^{2}=4\right.$, d.f. $1, n=4, p<0.05$; Fig. 3). The performance of pups was not affected by whether the test does were their mothers or not.

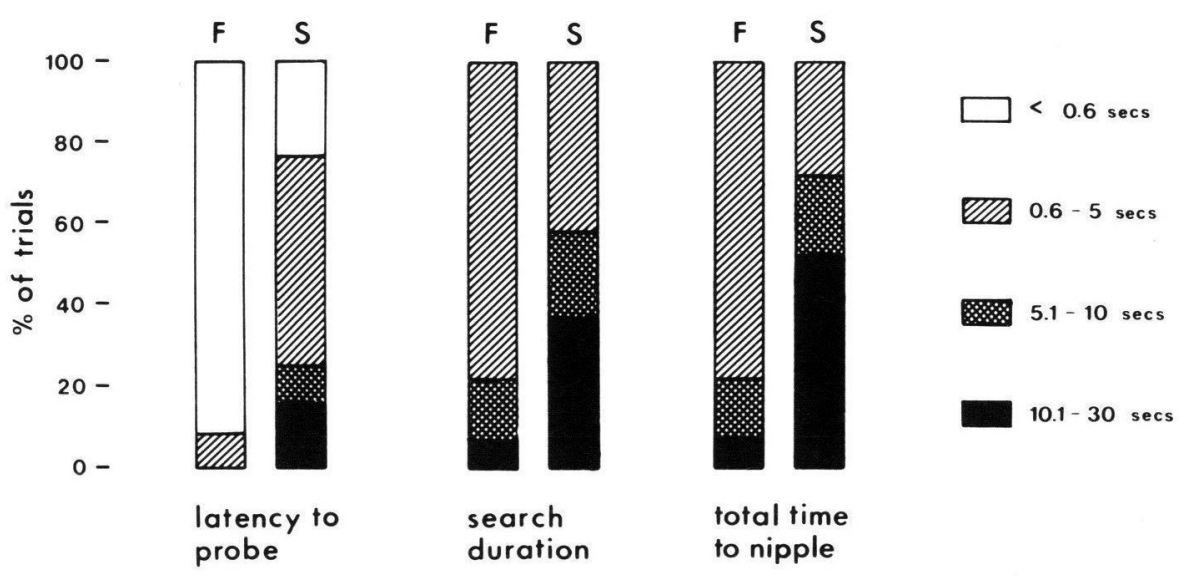

Fig. 3. Nipple search performance of 4-day-old pups tested in the arena on furred (F) and shaved (S) does.

To test the possibility that fur releases nipple search behaviour, pups were placed on a freshly shaved "fleece". They responded by pushing their muzzles into the fur and making some lateral head movements, but failed to show sustained searching. This was not due to possible adversive qualities of the adhesive used in making the fleece as all pups showed normal searching and took nipples on the doe which had been sprayed with adhesive.

The role of skin and nipples.

The previous findings suggested properties of the skin itself to be critical in sustaining effective nipple search behaviour. This was investigated by 
covering the skin and nipples in different ways. Table 2 summarizes the results of the conditions A-H shown in Fig. 4 and referred to below by capital letters.

The importance of the skin in releasing and sustaining nipple searching movements was demonstrated by covering the belly skin of a doe with adhesive tape and leaving the nipples bare (A). In this condition, pups did not initiate searching movements, and probed and took nipples only when they chanced to bring their noses next to them.

A

$>5 \mathrm{k}$

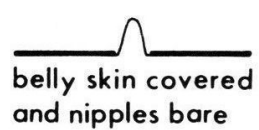

$E$

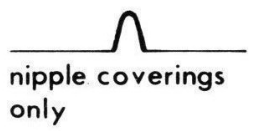

B
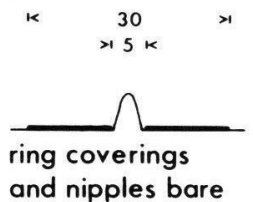

$\mathbf{F}$
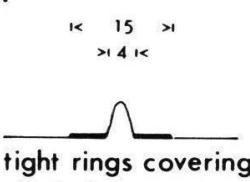

nipple bases
C

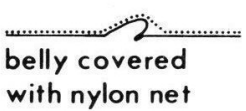

G
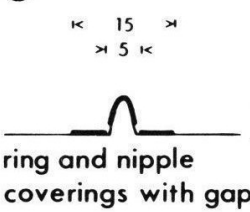

D k $15>$

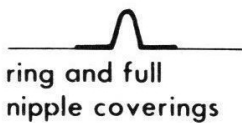

H

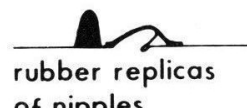

Fig. 4. Test conditions used to cover the doe's ventrum (A-H). Heavy lines indicate the areas covered, and diameters of tape rings and holes are indicated $(\mathrm{mm})$.

When limiting the tape to the nipple areas only (B), all pups showed searching movements and found nipples. However, arriving at the borders of the taped areas, they had difficulty crossing the $12.5 \mathrm{~mm}$ of tape to the nipple and spent an average of 6.5 secs probing at the border. Once they reached nipples they probed at and took them without delay.

To remove the tactile qualities of the nipples, a doe's belly was covered with a tight fitting nylon net $(C)$. Unexpectedly, pups failed to show nipple search behaviour but attempted to grasp nipples through the net when apparently random movements brought their noses directly over them.

In the next condition it was attempted to preserve tactile qualities and to remove possible odour cues of the nipples. To do this, the doe's nipples were fitted with small rings of adhesive tape and with a thin film of rub- 
TABle 2. Performance of pups (day 4) tested after covering the doe's ventrum in various ways (c.f. Fig. 4)

\begin{tabular}{|c|c|c|c|c|c|c|c|c|}
\hline Conditions & A & $\mathrm{B}$ & $\mathrm{C}$ & $\mathrm{D}$ & $\mathrm{E}$ & $\mathrm{F}$ & G & $\mathrm{H}$ \\
\hline $\begin{array}{l}\text { Probing outside } \\
\text { nipple area }\end{array}$ & - & 30 & - & 26 & 28 & 29 & 29 & 29 \\
\hline Probing in nipple area & 5 & 29 & 4 & 27 & 28 & 29 & 29 & 29 \\
\hline Nipples sucked & 4 & 29 & - & - & 15 & 9 & 7 & - \\
\hline $\begin{array}{l}\text { Percent of nipples } \\
\text { sucked after location }\end{array}$ & $80 \%$ & $100 \%$ & - & - & $54 \%$ & $30 \%$ & $24 \%$ & - \\
\hline
\end{tabular}

The number of trials $(\mathrm{N}=30)$ in which pups responded positively is given.

ber material (D). Pups now completely failed to grasp nipples although they probed vigorously at the borders of the rings. They continued to search to the end of the test trials ( 30 secs), and spent a total of $78 \%$ of the searching time probing in the nipple area.

To investigate further the location of supposed odour cues for nipple grasping, either nipples alone (E) or nipple areas (F) were covered. Although pups rapidly located and mouthed nipples in both conditions, they had difficulty in grasping and sucking even the bare nipples in condition $F$. When both nipples and nipple areas were covered so as to only leave a narrow gap at the nipple bases $(G)$, the results were similar.

To test how far from nipples stimuli releasing grasping and sucking would be potent, rubber replicas were stuck within $5 \mathrm{~mm}$ of the real nipples which were taped over $(\mathrm{H})$. Pups located these artificial nipples, but despite vigorous probing and repeated attempts at grasping, failed to take them, although they did not appear different in texture to the rubber covered nipples of condition $\mathrm{E}$.

\section{Skin temperature.}

Investigating the possibility that a temperature gradient may contribute to nipple location, the belly temperature of a lactating doe was measured. Repeated readings taken from beside nipples, in the centre of the doe's belly and at points mid-way between the centre and nipples, indicated an even skin temperature of $37 \pm 0.2^{\circ} \mathrm{C}$. Pups were then tested on the doe before and after the temperature of the nipple areas had been temporarily lowered to $22 \pm 5^{\circ} \mathrm{C}$ using ice packs. A comparison of the times taken to locate nipples under the two conditions using the Wilcoxon test showed them not to be significantly different $(T=10, n=6, p>.05)$. 
Virgin and pregnant does.

When two litters were tested on virgin does the pups pushed their heads into the fur and made some lateral head movements. However, this was accompanied by vigorous digging movements with the forepaws, a behaviour pattern not shown on lactating does. Sustained searching was not shown, and no nipples were taken. When these litters were tested on pregnant does, they searched vigerously and all located, grasped and sucked nipples in less than 10 secs. When the nipples of a virgin doe were coated with saliva taken from lactating does, no nipples were taken and searching performance was not improved.

\section{Discussion}

As doe rabbits only nurse for a few minutes each day, the pups are under considerable pressure to find a nipple and suck. There appear to be several adaptations to the short time the doe spends in the nest. One is the ability of pups to drink up to $25 \%$ of their own weight at one time (Lincoln, 1974); another is the pre-nursing arousal shown by pups in anticipation of their mother's arrival (Hudson \& Distel, 1982), as rat and cat mothers often wake and stimulate their young to suckle (RosenblatT \& Lehrman, 1963; Schneirla et al., 1963).

In addition, this study demonstrates that rabbit pups are able to locate nipples quickly and reliably by performing a highly stereotyped sequence of behaviours in response to a series of specific stimuli presented by the nursing doe. Pups respond to the vibrational and tactile stimuli associated with the doe's arrival with rearing movements. Once the doe is positioned over them, rearing brings the pups' heads in contact with the doe's belly fur, and this guides their muzzles onto her under-fur and skin, and stimulates lateral head movements. Cues on the skin then release the probing movements characteristic of nipple search behaviour, while cues at the nipples appear necessary for the release of nipple grasping. This is then followed by the pups sucking and switching nipples.

Considering the pressure under which pups must suckle, it is surprising to find the time they spend on nipples still further reduced by nipple switching. The average rate of 2.6 switches per minute observed in this study means that a pup spends on average only about 110 seconds on nipples during a 3 minute nursing session. The function and causes of nipple switching are not clear, as it has been observed to occur at similar rates to those reported here on anaesthetized does (Drewetr et al., 1982). As 
milk flow is blocked by anaesthesia (CRoss, 1953), nipple switching is apparently independent of the nipples' milk yield.

The components of nursing behaviour have also been studied in detail in the cat and rat. Stimuli presented by the mother and used by the young to locate and secure nipples are essentially similar in these species, although different emphasis has been given to the use of olfactory and tactile modalities in suckling behaviour.

Kittens are reported to nuzzle through the mother's fur by making side-to-side head movements until the bare nipple area is encountered. There, nuzzling changes to nose tapping until contact with the protruding nipple elicits grasping (Prechtl, 1952; Rosenblatt, 1971). While the role of tactile stimuli in nipple location and grasping has been mainly investigated (RosenblatT, 1971; 1977), removal of the olfactory bulbs in kittens at various ages has a disruptive effect (Kovach \& KLING, $_{\text {, }}$ 1967).

Rat pups also scan the body surface of the mother with the snout by performing side-to-side head movements (Prechtl \& Schleidt, 1950) until a nipple is contacted. They then probe the nipple with the tongue before grasping it (BLASS \& TEICHER, 1980). Olfactory bulb removal or nasal irrigation with zinc sulfate reportedly impairs nipple location and attachment, and decreases nosing of the mother's ventrum (SINGH et al., 1976). Washing the mother's ventrum or nipples disrupts nipple attachment by the pups, although nosing behaviour appears essentially unaffected (Hofer et al., 1976; TeICHER \& Blass, 1976). Normal suckling can be reinstated, however, by painting the nipples with distillate of the wash, with saliva from the pups or mother, or with amniotic fluid (TEICHER \& BLASS, 1976; 1977), or by injecting the mother with oxytocin (SINGH \& HofER, 1977). Shaving the mother's belly slows nipple location somewhat, but does not affect nipple grasping (Blass et al., 1977).

It has been suggested that for rabbit pups, a pheromone produced at the nipples is necessary for grasping behaviour, as distruction of the nasal mucosa or olfactory bulbs (SCHLEY, 1977), or displacing the entrance to the nostrils using tubing, disrupts it (MüLLER, 1978). Our observations suggest that not only the skin around nipples, but the entire belly, and indeed the whole body, produces a search releasing odour.

The nature of the odour is not clear. However, neither the presence of pup saliva (DREWETT et al., 1982) or doe's saliva on the nipples, nor milk appear important. The odour is not very far ranging, as pups placed on the taped belly of the test doe did not search for the uncovered nipples. 
Even in the net condition, odour concentrations were only sufficient at the nipples to bridge the mininal gap imposed.

Concentrated probing at the borders of the rings placed around nipples suggests that the odour cues form a gradient on the does's ventrum which may be used by pups as a map. Nipple grasping appears to be released either by the higher concentration of the search releasing odour at the nipple base or by a second odour there.

It has been suggested that thermal gradients or hair direction may be used by altricial young to locate nipples (Rosenblatt, 1976). However, neither peripheral cooling (Blass et al., 1977; MülLer, 1978), nor a negative thermal gradient as used in our tests, appear to interfere with nipple location. The presence of fur facilitates nipple location (Blass et al., 1977; MüLlER, 1978), and may affect suckling performance as demonstrated by our milk consumption tests. However, fur grain is unlikely to guide rabbit pups, as it does not appear to influence the direction of their movements. Fur helps the pups to encounter search, releasing odours on the doe and stimulates the apparently erratic lateral head movements. These may assist in the detection of the odour gradient, as on shaved does vertical, and therefore more localized probing movements predominate. In the normal nursing situation, fur may also function to sustain suckling behaviour by helping pups maintain contact with the mother's ventrum.

The odour releasing suckling behaviour is just one of a range of odours produced by rabbits and used in social communication (MукутоWYсz, 1972; Schalken, 1976). Use of the term "pheromone" for such odours has been cautioned as the response to the same signal my vary with social context and with the physiological state of the individual (MYкутоWYCZ, 1979). However, the highly stereotyped and reliable response of rabbit pups to the odour presented by the nursing doe seems to qualify it for consideration as a true pheromone.

Secretory activity of odour producing glands varies with age, sex and reproductive condition (Goodrich \& MYKYTowycz, 1972) and is hormonally controlled (Ebling, 1977). As production of the nipple search is correlated with the doe's reproductive status and time of year (Hudson \& Distel, in prep.), it is also likely to be under hormonal control.

\section{Summary}

The suckling behaviour of domestic rabbit pups was studied by observation from below through a glass-bottomed nest box ( 3 litters), and stimuli relevant for nipple location were investigated experimentally by shaving and covering does' bellies in various ways (16 litters). 
1. Rabbit pups are able to secure and suck nipples within seconds of their mother's arrival. They respond to the vibrational and tactile stimuli with rearing movements. Contacting the doe's fur, they push their muzzles into it and display probing and rapid lateral head movements characteristic of nipple search behaviour until a nipple is grasped.

2. Odour cues on the skin elicite and sustain nipple search behaviour, and appear to increase in strength toward nipples. High concentrations or, possibly, a second odour at nipple bases, release nipple grasping.

3. Because of the short ranging action of the odour, fur may help the pups to initiate and keep contact with the mother's ventrum, and to detect the odour gradient by stimulating lateral head movements. However, neither fur direction nor thermal gradients appear important for nipple location.

4. Of the 3-4 minute daily nursing time does took on average 5.2 secs to assume the nursing posture and pups a median time of 11.5 secs to contact the doe's belly fur, and a median of 6.0 secs to reach and secure a nipple. Unexpectedly, the pups released and switched nipples frequently, on average 2.6 times per minute, thus further reducing the total time spent on nipples. However, the efficiency of pups improved with age and the percentage of nursing time spent sucking increased from about $47 \%$ to $72 \%$ during the first 12 days.

5. The nipple search releasing odour of rabbit does may be considered as a true pheromone as the behaviour elicited is reliable and highly stereotyped.

\section{References}

Blass, E. M. \& Teicher, M. H. (1980). Suckling. - Science 210, p. 15-22.

- - - - Cramer, C. P., Bruno, J. P. \& Hall, W. G. (1977). Olfactory, thermal, and tactile controls of suckling in preauditory and previsual rats. - J. Comp. Physiol. Psychol. 91, p. 1248-1260.

Cross, B. A. (1953). Sympathetico-adrenal inhibition of the neurohypophysial milk ejection mechanism. - J. Endocrinol. 9, p. 7-18.

Deutsch, J. A. (1957). Nest building behaviour of domestic rabbits under semi-natural conditions. - Brit. J. Anim. Behav. 5, p. 53-54.

Drewett, R. F., Kendrick, K. M., Sanders, D. J. \& Trew, A. M. (1982). A quantitative analysis of the feeding behavior of suckling rabbits. - Developm. Psychobiol. 15, p. 25-32.

Ebling, F. J. (1977). Hormonal control of mammalian skin glands. - In: Chemical signals in vertebrates (Muller-Schwarze, D. \& Mozell, M. M., eds). London. Plenum Press, p. 17-33.

Goodrich, B. S. \& Mүкүтоwycz, R. (1972). Individual and sex differences in the chemical composition of pheromone-like substances from the skin glands of the rabbit, Oryctolagus cuniculus. - J. Mammal. 53, p. 540-548.

Gotтlieb, G. (1971). Ontogenesis of sensory function in birds and mammals. - In: The biopsychology of development (Tobach, E., Aronson, L. R. \& Shaw, E., eds). New York. Academic Press, p. 67-128.

Grota, L. J. \& Adler, R. (1969). Continuous recording of maternal behaviour in Rattus norvegicus. - Anim. Behav. 17, p. 722-729.

Hofer, M. A., Shair, M. \& Singh, P. (1976). Evidence that maternal ventral skin substances promote suckling in infant rats. - Physiol. Behav. 17, p. 131-136.

Hudson, R. \& Distel, H. (1982). The pattern of behaviour of rabbit pups in the nest. Behaviour 79, p. 255-271.

Kovach, J. K. \& KLiNG, A. (1967). Mechanisms of neonate sucking behaviour in the kitten. - Anim. Behav. 15, p. 91-101. 
Lincoln, D. W. (1974). Suckling: A time-constant in the nursing behaviour of the rabbit. - Physiol. Behav. 13, p. 711-714.

Müller, K. (1978). Zum Saugverhalten von Kaninchen unter besonderer Berücksichtigung des Geruchsvermögens. - Gießen. Dissertation.

Myкүтоwycz, R. (1972). The behavioural role of the mammalian skin glands. Naturwiss. 59, p. 133-139.

- - (1979). Some difficulties in the study of the function and composition of semiochemicals in mammals, particularly wild rabbits, Oryctolgus cuniculus. - In: Chemical ecology: odour communication in animals (RitTer, F. J., ed.). Amsterdam. Elsevier, p. 105-115.

Prechtl, H. F. R. (1952). Angeborene Bewegungsweisen junger Katzen. - Experientia 8 , p. $220-221$.

- - \& SCHLEIDT, W. M. (1950). Auslösende und steuernde Mechanismen des Saugaktes. - Z. Vergl. Physiol. 32, p. 257-262.

Rheingold, H. L. (1963). Maternal behavior in the dog. - In: Maternal behavior in mammals (RHEINGOLD, H.L., ed.). New York. John Wiley \& Sons Inc., p. 169-202.

RosenblatT, J. S. (1971). Suckling and home orientation in the kitten: A comparative developmental study. - In: The biopsychology of development (TовасH, E., Aronson, L. R. \& Shaw, E., eds). New York. Academic Press, p. 345-410.

- - (1976). Stages in the early behavioural development of altricial young of selected species of non-primate mammals. - In: Growing points in ethology (Bateson, P. P. G. \& Hinde, R. A., eds). Cambridge. Univ. Press, p. 345-383.

- - \& Lehrman, D. S. (1963). Maternal behavior in the laboratory rat. - In: Maternal behavior in mammals (Rheingold, H. L., ed.). New York. John Wiley \& Sons Inc., p. 8-57.

Schalken, A. P. M. (1976). Three types of pheromones in the domestic rabbit, Oryctolagus cuniculus (L.). - Chemical Sens. Flavor 2, p. 139-155.

Schley, P. (1977). Die Ausschaltung des Geruchsvermögens und sein Einfluß auf das Saugverhalten von Jungkaninchen. - Berl. Münch. Tierärztl. Wschr. 90, p. $382-385$.

Schneirla, T. C., Rosenblatt, J. S. \& Tobach, E. (1963). Maternal behavior in the cat. - In: Maternal behavior in mammals (RHEingold, H. L., ed.). New York. John Wiley \& Sons Inc., p. 122-168.

Singh, P. J. \& Hofer, M. A. (1978). Oxytocin reinstates maternal olfactory cues for nipple orientation and attachment in rat pups. - Physiol. Behav. 20, p. 385-389.

- - Tucker, A. M. \& Hofer, M. A. (1976). Effects of nasal $\mathrm{ZnSo}_{4}$ irrigation and olfactory bulbectomy on rat pups. - Physiol. Behav. 17, p. 373-382.

Teicher, M. H. \& Blass, E. M. (1976). Suckling in newborn rats: eliminated by nipple lavage, reinstated by pup saliva. - Science 193, p. 422-425.

- $\&$ \& $-(1977)$. First suckling response of the newborn albino rat: The roles of olfaction and amniotic fluid. - Science 198, p. 635-636.

VENGE, O. (1963). The influence of nursing behaviour and milk production on early growth in rabbits. - Animal. Behav. 11, p. 500-506.

Zarrow, M. X., Denenberg, V. M. \& Anderson, C. O. (1965). - Rabbit: Frequency of suckling in the pup. - Science 150, p. 1835-1836. 